\title{
Representação, deriva e adoecimento: espaço urbano e anamorfose expressionista em dois romances da literatura brasileira
}

\author{
Marcus Rogério Salgado \\ Universidade Federal do Rio de Janeiro
}

\begin{abstract}
Resumo
O presente artigo propõe um estudo comparativo entre duas obras da literatura brasileira produzidas em 1940 e 1954 - Inácio (Lúcio Cardoso) e Noite (Érico Veríssimo) - a partir do uso comum de estratégias estéticas expressionistas e de uma tematização do ato de deambular pelo espaço urbano, ligado diretamente ao adoecimento e à exclusão, configurando, assim, um quadro de relações entre forma literária, subjetividade e processo social.
\end{abstract}

Palavras-chave: literatura e espaço urbano; expressionismo; modernismo brasileiro.

\begin{abstract}
The aim of this article is to produce a comparative study involving Inácio (Lúcio Cardoso) and Noite (Érico Veríssimo), both novels published in-between 1940 and 1950's. They are approached by the common use of expressionistic stylistic devices, and by tematizing the act of deambulation (directly linked to illness and exclusion), in order to trace a frame of possible relations involving literary form, subjectivity and social process.
\end{abstract}

Keywords: literature and urban space; expressionism; Brazilian modernism.

Recebido em: 28/05/19

Aprovado em: 29/07/19

Neste estudo em tríptico, nosso objetivo é aproximar dois romances da literatura brasileira publicados entre as décadas de 1940 e 1950, nos quais a deambulação pelo espaço urbano ocupa lugar central na narrativa e em que, de par com a experiência do contínuo deslocamento (vivida sob o signo do trauma e do adoecimento), são arregimentados recursos estilísticos conformes ao expressionismo para a representação de tal experiência. Os romances são: Inácio (1940), de Lúcio Cardoso, e Noite (1954), de Érico Veríssimo.

A hipótese a partir da qual se constrói o presente artigo é a de que os dois romances agenciam procedimentos estilísticos próprios da estética expressionista, tematizando a deambulação e os processos locais de urbanização a partir da experiência traumática vivenciada 
no espaço social. Desse modo, nas duas obras é possível encontrar uma articulação da forma literária com o campo da subjetividade e com os processos sociais obtida a partir da aplicação de procedimentos estéticos específicos e da presença de uma lente dupla que aponta para o subjetivo e para os dados sociais ao mesmo tempo.

\section{Técnica expressionista e romance}

Publicados em 1940 e 1954, os dois romances ora estudados podem ser considerados manifestações da estética expressionista no âmbito da literatura brasileira. A recepção do expressionismo pelo modernismo demandaria estudo particular, mas vale lembrar que já havia nos quadros da literatura e da arte brasileiras uma pequena linhagem de textos e obras visuais com fatura expressionista. A começar por Anita Malfatti, atingindo seriamente Mario de Andrade, que estudou o movimento e agenciou algumas de suas ideias na crítica de arte e algumas de suas técnicas em obras como Amar, verbo intransitivo. Está presente nas obras de Lasar Segall e Osvaldo Goeldi, nas quais o gesto plástico se vincula diretamente com o pathos expressionista, em uma espécie de amplificação gráfica de uma experiência de mundo marcada pelo trauma, atingindo, ainda, parte da obra pictórica de Flávio de Carvalho. Verifica-se, também, na obra gráfica e literária de Cornélio Penna o influxo do expressionismo, o mesmo valendo para certos momentos da vasta bibliografia de Octavio de Faria (particularmente Os loucos) e para Guerra dentro do beco, de Jorge de Lima. Também Angústia (Graciliano Ramos) e Os ratos (Dyonélio Machado) são romances da década de 1930 em que as técnicas expressionistas são incorporadas entre os princípios de composição.

Embora Inácio e Noite não se possam conformar estritamente nos domínios do expressionismo enquanto estilo de época - por conta de uma desvinculação cronológica (uma vez que o expressionismo na literatura e na arte alemãs remonta às duas primeiras décadas do século XX) - , são obras que se utilizam de recursos estilísticos e técnicos característicos daquele movimento.

Antes de tudo, cabe ressaltar quais seriam os recursos estilísticos e técnicos mencionados. Para tanto, é preciso lembrar que o expressionismo propugnava uma ruptura com a representação objetiva da realidade, sobrepondo a experiência emocional (pathos) à percepção estritamente física do mundo, dos seres e dos entes. Ao processar a informação obtida na realidade empírica pelo aparato pathográfico que configura seu protocolo de escrita, o expressionismo privilegia o efeito plástico obtido pela anamorfose, que é uma forma de distorção representacional de imagem obtida em acesso ao real.

A anamorfose é responsável pelo processo de transfiguração da realidade implicado na estética expressionista. Essa representação da realidade mediante o processamento anamórfico pela subjetividade é constante nos três romances estudados — e, como veremos na segunda parte deste artigo, a anamorfose expressionista está diretamente vinculada à experiência urbana. 
Tal estratégia de transfiguração plástica das matérias extraídas do real se apresenta com mais força em Lúcio Cardoso. Antes de publicar Inácio, o autor mineiro já pautara outras obras pela estética expressionista, como Maleita (em que a percepção é alterada pela febre) e Salgueiro (texto que traz ambientação típica do realismo social, mas executado em técnica expressionista), sendo possível afirmar que ela estaria presente, em diferentes medidas, em textos posteriores, como $O$ enfeitiçado ou mesmo Crônica da casa assassinada, já que, na opinião de Mario Carelli, a escrita de Lúcio seria atravessada por "uma visão expressionista da tragédia humana" (Carelli, 1996, p. 636). Sem falar na poesia de Lúcio Cardoso, em que, marcada pelo contínuo gesto de deformação do real presente em sua lírica, percebe-se aquele "signo trágico de destruição" (Modern, 1958, p. 51) característico do expressionismo, herdeiro da melancolia e da angústia românticas.

Rogério Palma, protagonista de Inácio, tem um olhar que é assim descrito por uma prostituta da Lapa: "olhos que fitam sem ver, como se estivessem voltados para dentro" (Cardoso, 2002, p. 29). Aqui, vale retomar as palavras de Lotte Eisner, pois elas tornam explícito como esse olhar voltado para dentro, que fita sem ver (estabelecendo, portanto, uma relação apriorística com o mundo considerado enquanto representação mental), é caracteristicamente expressionista: "O expressionismo não vê — tem visões. Segundo Eschmid, 'a cadeia dos fatos: fábricas, casas, doenças, prostitutas, gritos, fome’ não existe; só existe a visão interior que eles produzem" (Eisner, 1960, p. 13).

Um notório recurso estilístico do expressionismo é o jogo entre luz e sombra, que, a bem da verdade, encena a dialética entre o visível e o invisível - e não por acaso uma das obras teóricas mais importantes do movimento foi justamente $O$ homem visivel, de Bela Balazs. Para Lotte Eisner, o claro-escuro deve ser considerado como "um atributo essencial do expressionismo" (Eisner, 1960, p. 34).

O jogo de luz e sombra, à maneira dos contrastes encontrados nos filmes de Murnau ou Fritz Lang, é aqui levado para o plano metafísico da disputa entre bem e mal pela hegemonia na casa do Ser. Assim, são frequentes ao longo do romance as situações em que a transfiguração da realidade se dá mediante alteração da percepção por fenômeno óptico ligado aos efeitos de luz. Recém-curado de uma longa enfermidade, Rogério Palma deambula pela cidade intoxicado pelo movimento das ruas. Chega até o Mercado e ali são plenos os efeitos provocados pela anamorfose expressionista, com a confusão completa entre o estado anímico de Rogério (paranoico) e a realidade circundante:

E tudo ali, naquele momento, causava-me terror, desde as verduras amontoadas, que assumiam aspectos horripilantes, até os vultos dos vendedores, ainda meio indistintos à luz da madrugada e ocupados em arrumar as mercadorias sobre as bancas. (Cardoso, 2002, p. 67) 
Mesmo as técnicas de representação teatral características do expressionismo - nas quais o esgar e o ríctus desempenham papel preponderante, baseados que são no princípio da deformação - se fazem presentes em passagens como esta: "Só nesse instante Inácio se voltou: vi então seu rosto pálido como se fosse de cera, corado ao centro, um rosto realmente de boneca, mas iluminado por tal expressão de ódio como jamais vi numa fisionomia humana" (Cardoso, 2002, p. 88).

Transcorrendo durante a noite e a madrugada, predominam em Noite as ambientações pouco iluminadas e sombrias, quando não as trevas.

Do protagonista não são apresentadas características materiais marcantes, sendo certo que a descrição definitiva de seu aspecto físico é apresentada logo na primeira página do romance e diz respeito ao olhar do "Homem de gris", que revela pupilas não apenas transfiguradas, como também transfiguradoras da realidade circundante:

Era um homem de estatura mediana, teria quando muito trinta anos, trajava roupa de tropical gris e estava sem chapéu. Quem, entretanto, lhe examinasse o rosto mais de perto, notaria algo de anormal naqueles olhos cujas pupilas ora se esvaziavam, como as de certos loucos, ora se aninhavam dum atônito fulgor de medo, como as dum animal acuado. (Veríssimo, 1978, p. 1).

O protagonista é frequentemente atirado "em abismos vertiginosos, em sucessivas quedas no vácuo" (Veríssimo, 1978, p. 2); não raramente, em cisma, perde-se "num território crepuscular, povoado de vozes e vultos vagos" (Veríssimo, 1978, p. 12), traçado pelos ângulos de sua psique.

Portanto, desde a primeira cena, o leitor é preparado para receber as representações da realidade advindas de uma percepção transtornada, engendradas por um olhar em cujas pupilas se registra o brilho da loucura - e nada mais apropriado às anamorfoses representacionais características do expressionismo do que esse olhar e essa percepção transtornados. Veja-se como a cidade é percebida, em vertigem, pelo Homem de gris:

Com o rosto colado ao poste, o Desconhecido escutava os ruídos da noite: o tropel e as vozes indistintas dos transeuntes na calçada; a surda trovoada do tráfego riscada pelo trombetear das buzinas e, a intervalos regulares, pelo tilintar das campainhas das sinaleiras.

A cidade parecia um ser vivo, monstro de corpo escaldante a arquejar e transpirar na noite abafada. Houve um momento em que o homem de gris confundiu as batidas do próprio coração com o rolar do tráfego, e foi então como se ele tivesse a cidade e a noite dentro do peito. (Veríssimo, 1978, p. 2)

Segundo Mario de Andrade - que estudou e também fez uso de procedimentos característicos da estética expressionista —, a deformação da realidade é "o princípio básico 
do Expressionismo" (ANDRADE, 1980, p. 237), uma vez que "ainda pela deformação o artista consegue conservar o espectador dentro da sensação de arte" (ANDRADE, 1980, p. 237), funcionando simultaneamente, portanto, como princípio estético e efeito.

O outro recurso estilístico do expressionismo - o jogo entre luz e sombra - também é usado com recorrência em Noite. A passagem em que os personagens irrompem em um velório ilustra bem o uso dos efeitos de luz e sombra tipicamente expressionistas no romance de Veríssimo:

A cabeça agora lhe doía com mais intensidade, as têmporas latejavam, e o calor ambiente, o aperto, a proximidade desagradável daquelas caras cujas feições mal distinguia à luz amarelenta da lâmpada nua, o contato daqueles corpos que transpiravam, o cheiro de cera derretida mesclado com o de suor humano e com o aroma das flores - tudo isso contribuía para aumentar-lhe a aflição, o estonteamento, a miséria. Houve um instante em que teve a impressão de que ia desmaiar. Apoiou-se na parede caiada e ficou a olhar estupidamente o cromo do calendário ali dependurado: um penhasco negro batido pelas ondas do mar. (Veríssimo, 1978, p. 39).

Os cenários do romance confirmam: a presença reiterada de becos e ruelas remete às perspectivas arquitetônicas vertiginosas e angulosas de filmes como $O$ gabinete do Dr. Caligari, pedra de toque do expressionismo fílmico.

Mas é no jogo cênico que de forma mais direta Noite incorpora a dinâmica expressionista, num sentido efetivamente teatral, no plano da representação. Como na dramaturgia expressionista prescrita por Max Reinhardt (seu principal encenador), pode-se afirmar que, em Noite, "surgiam com frequência cenas breves e intensas iluminadas no meio das trevas" (EISNER, 1960, p. 35). A técnica expressionista de exposição dos contrastes foi levada no romance para o sequenciamento e o encadeamento do enredo, qual força centrípeta.

\section{Forma literária, subjetividade e processo social}

Em seu estudo sobre o expressionismo, Jean-Michel Palmier afirma que, embora seja contemporâneo a outros movimentos de vanguarda (como o futurismo, o cubismo e até mesmo o dadá) e herdeiro da linhagem de rebelião poética romântica (com quem partilha, em grande medida, a Weltanschauung), esse programa estético manifestou sua especificidade também em decorrência de condições espaciotemporais igualmente específicas, vinculadas ao processo de urbanização de Berlim.

Neste sentido, não deixa de ser possível afirmar que os dois romances ora estudados parecem convergir para aquilo que Roberto Schwarz chama de "romance da urbanização" (SCHWARZ, 1992, p. 27), tipo específico de narrativa do século XX na qual seria possível encontrar os impasses e contradições implicados na passagem de uma formação social a outra - do Brasil agrário (explorado à exaustão pela geração anterior, a do realismo social de 
ambientação rural) ao "país em via de urbanização e industrialização" (GIL, 1997, p. 6). Assim, romances como $O$ amanuense Belmiro, Angústia e Os ratos serão exemplos desse tipo de narrativa da urbanização, na qual se "capta e estiliza uma experiência histórica específica cujo caráter virtual figura o antagonismo e o choque constituintes de duas temporalidades históricas irreconciliáveis na experiência de vida de nossos personagens" (GIL, 1997, p. 9).

A vivência de um processo histórico específico, diretamente ligado à entrada em cena da urbanização e do industrialismo, lastreia e percorre os dois romances, ainda que em diferentes medidas e tons. Se no tocante à utilização de recursos estilísticos expressionistas há convergência e simetria, no que diz respeito àquilo que Antonio Candido chama de "influências concretas exercidas pelos fatores socioculturais" (CANDIDO, 2011, p. 31) verificam-se a assimetria e a diferença entre as duas obras. Tentemos compreendê-las.

Em "A literatura e a vida social", Antonio Candido sinaliza para a possibilidade de os dados sociais serem objeto, em diversos graus, de um processo de "sublimação" (CANDIDO, 2011, p. 30) pelo texto. Prosseguindo na terminologia de cariz psicanalítico, poder-se-ia expandir a proposição de Candido, ressaltando como os dados sociais podem ser objeto, em diversos graus, de processos de sublimação (Sublimierung) e recalque (Verdrängung) pelo texto, e delineando-se, assim, uma posição tríplice para o texto literário onde forma estética, subjetividade e processo social se relacionam e articulam.

A partir desse enquadramento, seria possível afirmar que Inácio e Noite são textos revestidos por uma opacidade propositada em relação aos dados sociais, articulados num jogo de velamentos e desvelamentos, pelo qual se permitem flagrar os mecanismos de sublimação e recalque.

Isso ocorre de forma indireta em Inácio. Ambientado quase todo em uma faixa territorial que vai do Catete à Lapa (com escapadas à praia de Santa Luzia, à praça Quinze e a Copacabana), é impossível deixar de remontar o tempo da narrativa ao tempo histórico, coincidente com a Era Vargas e a sede do Governo Federal localizada nesse bairro histórico do Rio de Janeiro, transformado na corte do ditador gaúcho, que, no Palácio do Catete, morava e despachava - e onde fatidicamente iria morrer. Com as decisões monocráticas de Vargas, o Catete tornou-se o centro de irradiação do poder político e administrativo. Ao longo das décadas de 1930 e 1940 o pacato bairro com sua população de habitantes de pensões (caso do protagonista de Inácio) passou por alterações em sua reconfiguração espacial sincrônicas à presença desse poder irradiador, o que incluiu a construção de edifícios modernos, cinemas (São Luiz, Excelsior e Azteca) etc.

O pano de fundo, portanto, é a fase de "criação de um meio geográfico artificial" (SANTOS, 1997, p. 41), característica do industrialismo e da exploração urbana do espaço, com a emergência de uma "paisagem cultural” (SANTOS, 1997, p. 42), em substituição à paisagem natural. Se isso implica profundas transformações nos fluxos e nos itinerários (por conta dos meios de transporte e das reformas urbanísticas), a subjetividade não estará inteiramente blindada aos efeitos da paisagem artificial urbana. Segundo Milton Santos, "tudo isso se dá em 
um quadro de vida onde as condições ambientais são ultrajadas, com agravos à saúde física e mental das populações" (1997, p. 43).

De fato, em Inácio há sempre a atmosfera de turbulência e de desespero niilista experimentados pelas personagens e que parece sinalizar, a contraluz, para a confusão e o caos ideológico experimentados no plano social. Estamos no âmbito do Estado Novo, com seu projeto de industrialização do Brasil, com a criação do DIP e seus dispositivos ideológicos de controle da produção literária e artística. O clima febril com que Rogério Palma é acometido no início da narrativa conduz diretamente aos ânimos igualmente febris e delirantes pelos quais o país atravessava o Estado Novo. Por mais focado que seja em um drama psicanalítico, Inácio carrega, na marca-d'água, as cenas de um momento histórico e social bastante específico do Brasil na década de 1940. Tanto no texto como no Brasil daquele momento, algo se passa nos porões, uma força ctônica se move, a provocar espasmos subterrâneos.

Mesmo morando na capital federal e circulando pelas partes da cidade destinadas ao exercício do gozo, Rogério Palma despreza o conceito de "diversão" como lhe é oferecido pela urbe. Irônico, bebendo ao lado de uma prostituta, Rogério afirma: "Divertia-me, como se diz geralmente" (CARDOSO, 2002, p. 27). Seu cinismo lança um olhar de desdém à precária diversão oferecida às massas que denuncia o quanto mais ou menos de gozo (considerado como a ração bruta do real preparada a partir do Princípio do Prazer, Lustprinzip) é sonegado ou concedido a cada um, de acordo com sua posição sistêmica:

Voltamos vagarosamente à Lapa. E lá, diante de uma porta violentamente iluminada, detivemo-nos. Era uma dessas espeluncas de jogo, onde há de tudo: roleta, tiro ao alvo, prendas e não sei que mais. Ele me consultou com o olhar e eu concordei. Entramos. Furamos a multidão que estacionava à porta e ganhamos o comprido corredor onde as bancas e os alvos se alinhavam. Risos espocavam nos cantos, risos próprios dos locais onde existem aglomerações, roucos e intensos, que sempre puseram meus nervos à flor da pele, como se fossem uma bofetada que eu tivesse recebido em plena face. Um bêbado discutia com um dos banqueiros, ameaçando partir-lhe a cabeça com um taco. "Os homens se divertem", pensei. (CARDOSO, 2002, p. 80-81)

Também se desdobra em reiterados lances de sublimação e de recalque a presença dos dados sociais em Noite. A narrativa se passa numa cidade portuária, cujo nome não é mencionado, tal como ocorre com as personagens, que são identificadas por epítetos: tem-se o Anão e o Mestre, bem como o protagonista, identificado por "Homem de gris", que, padecendo de uma crise de amnésia, não se encontra em condições de fornecer informações sobre si. Estabelece-se, portanto, um continuum entre cidade anônima e personagens anônimos, pelo qual a modernidade urbana é experimentada de forma traumática no campo da subjetividade. Como frisa Ewerton Ignácio, as personagens de Noite encontram-se "enredadas nas duras malhas de uma sociedade bruscamente modernizada, reificadora e até alienante” (IGNÁCIO, 2006, p. 2). 
De qualquer forma, os signos de inserção na modernidade ao nível da superfície fazem-se presentes ao longo de toda a narrativa: a voragem urbana está ali, com o "zumzum informe das vozes" (VERÍSSIMO, 1978, p. 2), com "os faróis de automóveis que rodavam sobre o asfalto" (VERÍSSIMO, 1978, p. 4), com os "edifícios de janelas iluminadas" (VERÍSSIMO, 1978, p. 7) e com "um grande ônibus de janelas iluminadas e abarrotado de gente" (VERÍSSIMO, 1978, p. 4). A experiência urbana é vivida como um aleatório bombardeamento sensorial (ruídos, luzes, claustrofobia), a isolar o sujeito num lidar com signos, cuja função é nada menos que substituir a vida, blindando-o no interior de uma bolha emocional — a "noite particular" (VERÍSSIMO, 1978, p. 3), que constitui a vida anímica de cada unidade existencial precária a deslocar-se pelo eixo-realidade.

O tempo não produtivo numa cidade anônima como a de Noite só pode ser gasto com desperdício anímico. As opções são exíguas: um parque, um restaurante de cais, uma quermesse, um cabaré e um prostíbulo - sem falar no velório e no pronto-socorro, convertidos em lugares e situações de gozo. Toda a expectativa alimentada pela sociedade de massas de que fosse possível gerar "a ilusão de felicidade social através do entretenimento" (FERNANDES, 2009, p. 28) se vê questionada e posta em xeque. Como perceberiam os situacionistas, na década seguinte, as formas planificadas de sociabilidade são antinômicas à experiência (Erfahrung).

Noite representa, assim, a vivência traumática do espaço em uma metrópole que experimenta a modernidade periférica. Os lugares para o gozo são predeterminados pela instância coercitiva do aparato social e é neles que o mesmo deve realizar-se, a eles é que o mesmo deve confinar-se, como se parte do corpo dessa cidade permanecesse proibida ou vetada a alguns dos que por sua pele se deslocam. O corpo da cidade, assim, revela-se incapaz de oferecer a potência de gozo esperada pelo protagonista e não é por acaso que sua deambulação seja marcada pela angústia e pela impotência - que, em seu caso, é tanto a impotência de encontrar sua identidade (estado de amnésia) e de intervir sobre a realidade (estado de apatia) como aquela fisicamente definida, a rondar desde sempre, em relação fantasmática, o imaginário e a ideologia implicados nas representações concernentes e provindas do gênero dominante.

\section{À deriva}

Em que pesem os dois pontos anteriormente abordados (a fatura estética de corte expressionista e as formas de plasmagem da realidade sócio-histórica), é na tematização do ato de deambular pelo espaço urbano que os dois romances mais se aproximam e parecem mesmo encontrar-se em convergência.

Andar sem objetivo predeterminado - deslocando-se pelo espaço na contramão da organização do tempo de produção, regido por implacável teleologia — já se constituía uma forma de expressão da subjetividade desde a emergência, no século XIX, do flâneur. Contudo, a flânerie ainda estava ligada a uma ambiência urbana de passagens e de uma arquitetura 
labiríntica. Para o homem do século XX, na estufa artificial das cidades modernistas, só restava a deriva - ato de caminhada revestido de contornos socioculturais bem precisos e distintos, ainda que convergentes, aos da flânerie.

Nos anos 1950, os situacionistas definiriam da seguinte forma a deriva: "modo de comportamento experimental ligado às condições da sociedade urbana: uma técnica da passagem rápida por ambiências várias" (apud JACQUES, 2003, p. 65). Segundo Guy Debord,

uma ou várias pessoas que se dediquem à deriva estão rejeitando, por um período mais ou menos longo, os motivos de se deslocar e agir que costumam ter com os amigos, no trabalho e no lazer, para entregar-se às solicitações do terreno e das pessoas que nele venham a encontrar. (apud JACQUES, 2003, p. 87).

Essa entrega às solicitações dos lugares e das pessoas constitui o próprio elemento dinâmico das deambulações das personagens dos dois romances. No entanto, na deriva ela obedece a uma finalidade: "o dériveur realiza uma investigação psicogeográfica, e se espera que ele volte para casa tendo observado o modo como as áreas atravessadas ressoam com estados de espírito e ambiências particulares" (COVERLEY, 2014, p. 175). Assim, "a deriva se torna um artifício estratégico para o reconhecimento da cidade" (COVERLEY, 2014, p. 176) o que está em relação isomórfica com a busca por reconhecimento (de si e do espaço em torno) que preside os deslocamentos do Desconhecido pelo espaço urbano.

Inácio começa com o protagonista, Rogério Palma, lançando-se às ruas após uma enfermidade prolongada. Experimenta o ato de andar sem destino pelas ruas como algo que lhe altera a disposição anímica e a própria percepção do real, à maneira de um estupefaciente. Assim, para Rogério, depois de dois meses em reclusão, pisar as calçadas "embriagou-me como um tóxico" (CARDOSO, 2002, p. 21).

Nessas condições, andar pela cidade se converte, subitamente, em ato propiciatório de uma experiência epifânica, na qual a saturação no input informacional gerada pela vida urbana se converte numa espécie de "iluminação profana" (BENJAMIN, 1993, p. 23), diretamente ligada ao ato de deambular:

Tudo me pareceu extraordinário, e a vida, um acontecimento excepcional, digno de ser abençoado por todos os homens. Nada escapava à minha vista: à medida que ia andando, via os restaurantes abertos, modestos restaurantes onde os operários iam restaurar suas forças, os jardins, anêmicos jardins, que naquele instante me pareciam tão maravilhosos, carrinhos de crianças, as amas generosas, lojas, tudo, finalmente. Que grande espetáculo é a vida! (Cardoso, 2002, p. 22)

A epifania vivenciada por Rogério Palma é, por si, quase um manifesto em prol da vinculação entre cidade e subjetividade — mediada por um estado de privação física provocado 
pela enfermidade. Ou, como preferiria James Hillman, "a ligação entre alma cidade" (1993, p. 38) — já que "a alma existe na cidade" (1993, p. 38).

Nabusca por essa iluminação profana em ambiente urbano a que se refere Walter Benjamin, Inácio poderia ser aproximado com um dos mais importantes romances de deambulação do século XX: O camponês de Paris, de Louis Aragon. O que Jeanne Marie Gagnebin escreve para o romance surrealista de Aragon é válido para o ato de deambular em Inácio, sendo importante lembrar que a poesia de Lúcio Cardoso também contém "ecos do Surrealismo" (RIBEIRO, 2006, p. 55), que, de fato, são facilmente detectáveis na chamada "Trilogia do mundo sem Deus" (de que Inácio faz parte, ao lado de $O$ enfeitiçado e o inconcluso Baltazar):

As andanças do eu narrador no Camponês de Paris podem parecer o passeio esotérico de um sujeito esquisito nos labirintos de galerias equívocas, entre a baixa prostituição e a revelação do sagrado. Elas se descobrem como sendo, antes, a mensuração simultaneamente desvairada e exata de um labirinto espiritual, como o reconhecimento sempre reiniciado de pontos de fuga abissais. (GAGNEBIN, 1996, p. 252-253)

Se os dois são romances que celebram "o valor insubstituível da errância” (GAGNEBIN, 1996, p. 245), há, contudo, uma diferença entre Inácio e $O$ camponês de Paris: Rogério Palma deseja sistematizar o cinismo como uma forma de relacionar-se com o ambiente urbano, com o meio geográfico artificial que compõe a paisagem das metrópoles. Seu objetivo é antes uma libertação metafísica (no abismo que separa o Satori do Nirvana), sem implicar a "lucidez austera da militância revolucionária" (GAGNEBIN, 1996, p. 253), que, no entendimento de Jeanne Marie Gagnebin, caracterizaria a iluminação profana como concebida por Benjamin. Esse dado é importante, pois, de fato, a deambulação e a busca pela iluminação profana em Rogério Palma não implicam um gesto de jaez revolucionário. O âmbito pelo qual se move é, antes, o da rebelião — de uma rebelião a conter elementos simultaneamente luciferianos e cínicos.

Noite é, igualmente, um romance de deambulação. A personagem principal — só ou em companhia do Anão e do Mestre - se desloca por uma cidade que não é nomeada, durante uma madrugada agitada. São, assim, percorridos lugares os mais diversos, cujo sequenciamento proporciona a entrada em cena de tipos humanos e sociais os mais distintos: um restaurante popular, um bordel, um velório etc. A cidade de Noite é uma "cidade imaginária em segundo grau" (CORNELSEN, 2005, p. 69), pois, embora esteja desreferencializada (e chama atenção do leitor a ausência de referências toponímicas ou mesmo topográficas que permitam correlacionar a cidade representada como duplo de uma cidade específica no mundo empírico), pode-se-lhe perceber, à contraluz, as características facilmente identificáveis de uma metrópole construída no século XX em um país em estágio de desenvolvimento econômico, marcado pela existência de signos portáteis de prestígio socioeconômico que testemunham a irradiação da cultura urbana do centro para as margens. Ao contrário do Homem gris, o leitor estranha essa cidade imaginária, mas nela 
identifica sedimentações urbanísticas que remetem a paisagens culturais bem específicas. É uma cidade sem referências toponímicas ou topográficas, mas que remete a um modelo preexistente de cidade, a uma ambiência: a cidade moderna, polifônica, com sua pressão despersonalizadora e sua organização do espaço a partir de valores econômicos explicitamente definidos.

$\mathrm{O}$ adoecimento do Homem gris faz com que irrompa no interior da cidade uma outra cidade - que ele mesmo percebe ao penetrar em uma rua e, não a identificando, queixar-se do efeito que lhe causa essa percepção incerta do espaço urbano circundante: "parece outra cidade" (VERÍSSIMO, 1978, p. 23). Da mesma forma com que de dentro da cidade imaginária irrompe um duplo, essa mesma cidade imaginária é o duplo de um modelo de organização urbana característico do estado da modernidade em meados do século XX. À maneira de um jogo de espelhos, a cidade procura sua identidade (diluída nessa imagem genérica que se depreende de si: uma cidade moderna como qualquer cidade moderna, a ponto de prescindir de referências toponímicas e topográficas que a identifiquem e unam a uma cidade do mundo empírico) ao mesmo tempo que o Homem gris se reconhece como o Desconhecido que desconhece não só a cidade, como até a si mesmo. A cidade escapa de si, ainda que sinta a possibilidade de que no corpo da cidade se dê o reencontro consigo mesmo, carregando, assim, a ambiência urbana com a ambiguidade máxima: lugar que provoca a angústia (com a permanente ameaça de dissolução da subjetividade em seu interior), é nele que talvez ocorra a cura para o adoecimento. Aqui, a cidade imaginária é alimentada e alimenta aquilo que Merlin Coverley chama de "inconsciente urbano" (2014, p. 180). E, mais uma vez submetidos ao jogo de espelhos, a cidade e o Homem gris carregam, cada um, seus segredos, com a diferença que para o protagonista a própria cidade é um segredo, bem como a carga semântica que ela pode despertar-lhe. Como já sabia Guy Debord, "os segredos da cidade são decifráveis, mas o significado pessoal que eles têm para nós é incomunicável” (apud COVERLEY, 2014, p. 178).

Ao contrário do flâneur, para o Homem gris a caminhada é um ato carregado de angústia. Como se sabe, a angústia é um dos motores existenciais do expressionismo, sendo certo que o movimento é em grande parte definido por essas "visões de angústia" (PALMIER, 1979, p. 288), nas quais se materializa nada menos que o próprio "pathos expressionista" (PALMIER, 1979, p. 296), baseado em "uma distorção progressiva e minuciosa de toda realidade, ela mesma devorada pelo sentimento e pela emoção" (PALMIER, 1979, p. 296). Isso é potencializado pela associação previamente existente entre cidade moderna e angústia. Como salienta Bernardo Secchi, "a angústia acompanha o século, e a cidade para ser o lugar onde ela é delineada de modo mais evidente" (2015, p. 32).

O processo de desreferencialização causado pela perda da memória pessoal transforma a cidade em um labirinto. $\mathrm{O}$ labirinto se vincula, simultaneamente, à memória, ao infinito e à ausência, lembrança permanente da luta entre o visível e o invisível que se opera nos campos macro e micro da realidade empírica. E, com isso, subverte-se toda a razão planificadora da 
cidade moderna do século XX, uma vez que "dominado pela angústia, o século parece ter medo do infinito e do vazio que ele abre na sociedade e na consciência dos indivíduos" (SECCHI, 2015, p. 34). É assim que, duplamente desestabilizado, o espaço urbano em Noite torna-se um espaço dominado pela angústia e, sobretudo, pelo medo: "medo de uma sociedade reduzida a uma multidão indiferenciada, de um espaço ilimitado, de um tempo cada vez mais acelerado e privado de sequências reconhecíveis que cadenciam o fluir de maneira compreensível" (SECCHI, 2015, p. 34).

Nos dois romances, a deambulação encontra uma relação direta com processos de adoecimento. Em Inácio, Rogério Palma é tomado por verdadeiro delírio deambulatório após dois meses de reclusão por conta de uma pneumonia. Em Noite, o Homem de gris experimenta uma perda possivelmente temporária de memória. Rogério Palma e o Homem de gris deslocamse não para afugentar o tédio - como faria o flâneur oitocentista —, e sim movidos por uma pulsão direta de desespero e de angústia, diretamente ligada a seu adoecimento.

Também nos dois romances encena-se a experiência da deriva por personagens que se situam nas margens da sociedade de classes. Embora não tenhamos informações sobre os rendimentos de Rogério Palma, presume-se que ele viva uma existência parasitária, que lhe permite deslocar-se pelo corpo da cidade em fluxos distintos daqueles ditados pelo tempo da produção. $\mathrm{O}$ "Homem de gris" de Noite, embora traga uma carteira recheada de cédulas, é um inadaptado cuja subjetividade em fricção com o mundo atinge o ponto máximo de conflito ao perder a memória e assistir à transformação do espaço urbano quotidiano em um labirinto a céu aberto.

Ao trabalharem de forma conjugada a deambulação e o adoecimento, as duas obras parecem sinalizar para a existência de uma modalidade de desenraizamento que, na verdade, é vivenciado sob o signo do adoecimento. É uma forma de desenraizamento pelo qual a narrativa biográfica é interrompida abruptamente por uma situação traumática que estabelece na mesma um ponto de viragem, uma vez que ligada diretamente à alienação — considerada enquanto drama socioeconômico e como drama individual. Nas personagens das duas obras, encontramos aquilo que Gilberto Safra (1999) chama de desenraizamento nos níveis estético, ético e diante do sagrado, uma vez que em Rogério Palma e no Homem de gris encontramse percepções, respostas e relações com o real que se afastam do senso comum e se dirigem rumo à margem - temporariamente (como parece ocorrer com o Homem de gris, que retorna ao ambiente doméstico no final da narrativa - embora não saibamos ao certo com que ali se deparou) ou em estado de formulação (caso de Rogério Palma). Um e outro são corpos aos quais não é permitido o enraizamento, condenados a deambulações contínuas pelas margens e pelos espaços opacos. Se o que lhes é negado é o enraizamento, em alguma medida também o que lhes será negado é a cidadania, o direito de exercê-la — já que o enraizamento é "talvez a necessidade mais importante e mais desconhecida da alma humana" (WEIL, 1996, p. 411), pela qual ele participa do coletivo e projeta imagens possíveis de futuro. 


\section{Referências}

ANDRADE, Mário de. Obra imatura. São Paulo: Martins; Belo Horizonte: Itatiaia, 1980.

BENJAMIN, Walter. Magia e técnica, arte e politica. São Paulo: Brasiliense, 1993.

CANDIDO, Antonio. Literatura e sociedade. Rio de Janeiro: Ouro sobre Azul, 2011.

CARDOSO, Lúcio. Inácio [1940]. Rio de Janeiro: Civilização Brasileira, 2002.

CARELLI, Mário. Corcel de fogo: vida e obra de Lúcio Cardoso. Rio de Janeiro: Guanabara, 1988. . Crônica da casa assassinada: a consumação romanesca. In: CARDOSO, Lúcio. Crônica da casa assassinada. Edição crítica por Mário Carelli. San José: Editorial Universidad de Costa Rica, 1996.

CORNELSEN, Elcio. Berlin, cidade moderna. In: NAZARIO, Luiz (org.). A cidade imaginária. São Paulo: Perspectiva, 2005.

COVERLEY, Merlin. A arte de caminhar: o escritor como caminhante. São Paulo: Martins Fontes, 2014.

EISNER, Lotte. O écran demoníaco. Lisboa: Aster, 1960.

FERNANDES, Cintia San Martin. Sociabilidade, comunicação e política. Rio de Janeiro: E-Papers, 2009.

GAGNEBIN, Jeanne Marie. Uma topografia espiritual. In: ARAGON, Louis. O camponês de Paris. Rio de Janeiro: Imago, 1996.

GIL, Fernando Cerisara. O romance da urbanização. 1997. Tese (Doutorado em Teoria Literária) — Universidade Estadual de Campinas, Instituto de Estudos da Linguagem, Campinas, 1997.

HILLMAN, James. Cidade e alma. São Paulo: Studio Nobel, 1993.

IGNÁCIO, Ewerton de Freitas. Érico Veríssimo e o espaço romanesco: uma leitura de Noite, Revista Gatilho, Programa de Pós-graduação em Linguística da Universidade Federal de Juiz de Fora, ano II, v. 3, mar. 2006. Disponível em: https://periodicos.ufjf.br/index.php/gatilho/ article/view/26856/18538. Acesso em: 7 dez. 2019.

JACQUES, Paola Berenstein (org.). Apologia da deriva: escritos situacionistas sobre a cidade. Rio de Janeiro: Casa da Palavra, 2003.

MODERN, Rodolfo E. El Expressionismo literário. Buenos Aires: Nova, 1958.

PALMIER, Jean-Michel. L'Expressionnisme et les arts. Paris: Payot, 1979.

RIBEIRO, Ésio Macedo. O riso escuro ou o pavão de luto. São Paulo: Edusp, 2006.

SAFRA, Gilberto. A face estética do self. São Paulo: Unimarco, 1999.

SANTOS, Milton. Metamorfoses do espaço habitado. São Paulo: Hucitec, 1997.

SCHWARZ, Roberto. O pai de família. Rio de Janeiro: Paz e Terra, 1992.

SECCHI, Bernardo. A cidade do século vinte. São Paulo: Perspectiva, 2015. 
VERÍSSIMO, Érico. Noite [1954]. Rio de Janeiro: Globo, 1978.

WEIL, Simone. O enraizamento. In: BOSI, Ecléa (org.). A condição operária e outros estudos sobre a opressão. Rio de Janeiro: Paz e Terra, 1996.

\section{Minicurrículo}

Marcus Rogério Salgado é doutor em Literatura Comparada pela Universidade Federal do Rio de Janeiro (UFRJ) e mestre em Literatura Brasileira (UFRJ). Autor dos livros de ensaios $A$ vida vertiginosa dos signos e A arqueologia do resíduo: os ossos do mundo sob o olhar tropical. Traduziu obras de Jean Lorrain, Pierre Mabille, Ludovic Tac, Zhang Longxi e Ted Hughes. Lecionou Teoria da Literatura e Literatura Brasileira em instituições de ensino superior no Brasil (Universidade Federal Fluminense; Universidade de Brasília) e no exterior (Universidade de Santiago de Compostela). Atualmente é professor adjunto na Faculdade de Letras da UFRJ. 